\title{
Implementation and Control of Six-Phase Induction Motor Driven by a Three-Phase Supply
}

\author{
Mohamed I. Abdelwanis ${ }^{1, * \mathbb{D}}$, Essam M. Rashad ${ }^{2}$, Ibrahim B. M. Taha ${ }^{3}$ and Fathalla F. Selim $^{1}$ \\ 1 Electrical Engineering Department, Faculty of Engineering, Kafrelsheikh University, P.O. Box 33516, \\ Kafr El Sheikh 33516, Egypt; fateh.saleem@eng.kfs.edu.eg \\ 2 Electrical Engineering Department, Faculty of Engineering, Tanta University, P.O. Box 31111, \\ Tanta 31527, Egypt; emrashad@ieee.org \\ 3 Department of Electrical Engineering, College of Engineering, Taif University, P.O. Box 11099, \\ Taif 21944, Saudi Arabia; i.taha@tu.edu.sa \\ * Correspondence: mohamed.soliman4@eng.kfs.edu.eg
}

Citation: Abdelwanis, M.I.;

Rashad, E.M.; Taha, I.B.M.; Selim, F.F. Implementation and Control of Six-Phase Induction Motor Driven by a Three-Phase Supply. Energies 2021, 14, 7798. https://doi.org/10.3390/ en14227798

Academic Editors: Victor Becerra and Ahmed Rachid

Received: 20 October 2021

Accepted: 18 November 2021

Published: 22 November 2021

Publisher's Note: MDPI stays neutral with regard to jurisdictional claims in published maps and institutional affiliations.

Copyright: (C) 2021 by the authors. Licensee MDPI, Basel, Switzerland. This article is an open access article distributed under the terms and conditions of the Creative Commons Attribution (CC BY) license (https:// creativecommons.org/licenses/by/ $4.0 /)$.

\begin{abstract}
This paper is interested in implementing and controlling a modified six-phase induction motor (MSPIM) when fed from a three-phase supply either via an inverter or with a direct grid connection loaded by a centrifugal pump. The main aims of using the MSPIM are to enhance motor reliability and reduce torque pulsation. A three-to-six phase transformer has been designed, implemented, and employed to enable the SPIM to be driven from a three-phase supply. It is preferable to use the three-to-six phase transformers integrated with three-phase inverter on using the six-phase inverter to generate lower values of harmonics and lower steady-state error of speed and reduce the starting current and because also it isolates the primary circuit from the secondary, and the cost will be lower compared to the design of a special six-phase inverter. Dynamic models of SPIM, three-to-six phase transformer, and three-phase variable speed drive are derived. Then, a scalar (V/F) closed-loop control of SPIM is employed, and the results are discussed. Fine-tuning of PID controllers is used to keep the motor speed tracking the reference value. A low pass filter is connected to reduce the ripple of voltage and current waveforms. An experimental setup has been built and implemented to check the possibility of controlling SPIM by a variable speed drive system fed from a three-to-six phase transformer. It is found that the proposed method can be effectively used to drive the SPIM from a three-phase supply.
\end{abstract}

Keywords: PWM; six-phase induction motor; harmonic distortion; three-and six-phase transformers

\section{Introduction}

Induction motors (IM) are the most employed machines in the market, particularly in fixed-speed applications. They occupy about 70\% of the employed electric machines [1-4]. It is because they can work directly online and with inverters [5]. Further, they do not use rare-earth magnets, and thus they have a cheap cost. Standard induction machines are of three-phase configuration due to the high availability of three-phase grids.

The six-phase induction motor is characterized by improving the torque density and fault tolerance capabilities to reduce losses and improve the motor performance [6]. Multi-phase machines are gaining interest in several industrial applications, e.g., pumps, compressors, etc. [7-10].

Some researchers [11-13] introduced the multi-phase systems over six phases to verify the advantages of these systems compared to traditional ones. However, increasing the number of phases also increases the size of the inverter and complicates the associated control systems [14].

Among multi-phase systems, six-phase induction machines have been proposed in the literature [13]. It is because they can be rewound using existing standard three-phase stator frames. In [1,15], a comparison between three-phase and six-phase induction motors 
is given, both in a simulation environment and experimental laboratory tests. It is shown that the six-phase induction motors have higher torque density, increased speed stability, and reduced core losses [16,17].

However, to drive a six-phase induction motor, a six-phase inverter with a suitable control system is required, which increases the cost and complicates the system [18-21].

One advantage of induction machines is that the speed can be varied easily, either using open or closed-loop techniques. It makes this machine preferable in several applications where simplicity and reliability are key elements [22].

There are three types of IM controlling: the first type is (V/F) control, which aims to maintain constant magnetic flux at the rated value in the induction motor [23-26], the second is the flux vector method that was developed to control the magnitude of the ac voltage, and vector $[20,27]$, and the third is sensorless vector control to modify the amplitude, frequency, and phase of the drive voltage [28-30].

Phase conversion is needed in some high current applications, such as induction furnaces where a two-phase source is used. As such, a three-phase system in the utility grid is available. The higher the number of phases, more than three-phase supply is needed to supply the higher number of phases motor for operating or for testing [31-33]. The conversion from a three-phase source to a six-phase system is needed in AC/DC power electronic converter supply [34].

The six-phase source can be obtained from the three-phase system; three equal singlephase transformers are wanted with two coils in the secondary [35-39]. A pure sine wave six-phase fixed voltage and frequency is needed from a three-phase supply [40].

This paper proposes a drive system for the modified six-phase IM for both variable and constant speed applications. In variable speed applications, the conventional threephase inverter is connected to three single-phase primary and two secondary transformers. The three-to-six phase transformer is used to feed the modified six-phase motor [41]. The scalar V/F closed-loop scheme is used to control the speed of modified six-phase motor. In the case of constant speed applications, the inverter is not used where a three-to-six phase transformer is sufficient.

The structure of this paper is organized as follows: Section 1 presents the introduction, paper organization, and literature review. Section 2 presents the modeling of the three-to-six phase transformers. Section 3 presents the modeling of the three-phase inverter. Section 4 presents the modeling of the modified six-phase IM. Section 5 presents the control scheme that depends on the closed-loop control system. Section 6 presents the implementation of a six-phase IM operation from a three-to-six phase transformer fed from the three-phase variable speed drive. Finally, Section 7 concludes the outputs of the findings of this work.

\section{Modelling, Winding Arrangement, and Calculation of Six-Phase Transformer}

Three different transformers A, B, and C are built, each having one primary coil and two secondary coils; the three coils of the primaries are star-connected, while the six coils of the secondary side are coupled in a unique way to produce a star output. Figure 1 depicts the connection schematic of the primary and secondary windings to produce a three-phase star in primary and a six-phase star connected in secondary. 


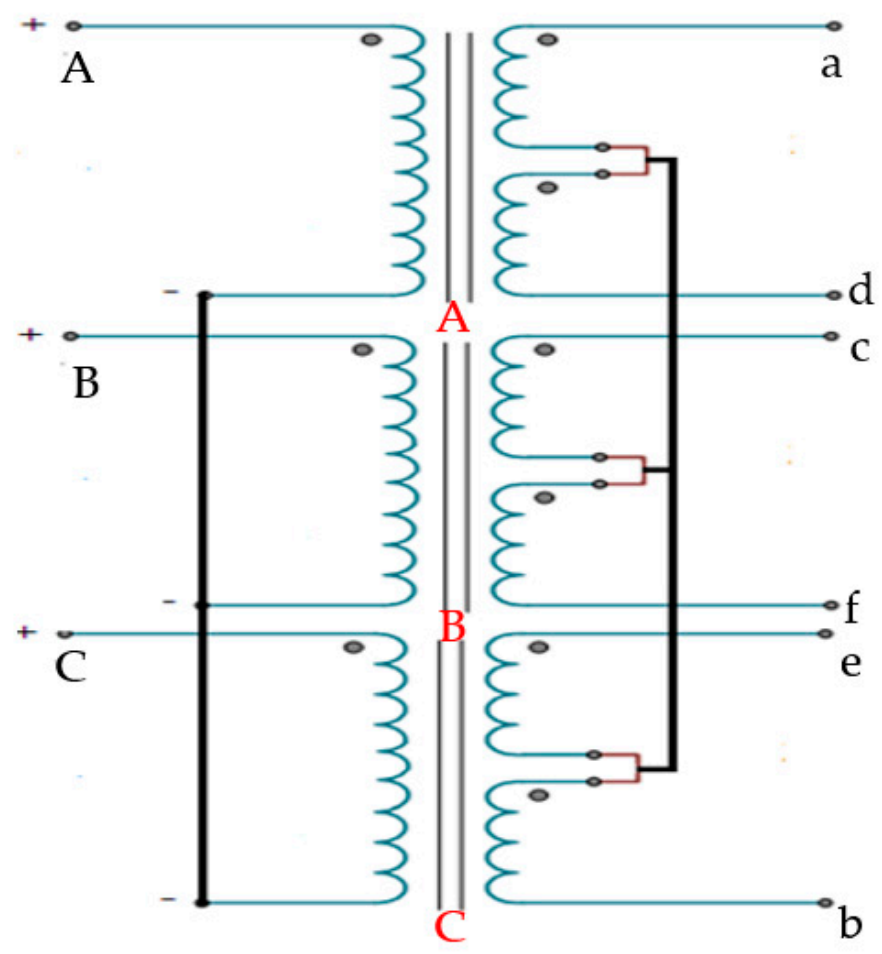

Figure 1. Three-to-six phase transformer connection.

The balanced output phase voltage (with phase angles of $60^{\circ}$ between each phase) is calculated using specified turn ratios. The following equation gives the input-output relation:

$$
\left[\begin{array}{l}
V_{a} \\
V_{b} \\
V_{c} \\
V_{d} \\
V_{e} \\
V_{f}
\end{array}\right]=\left[\begin{array}{ccc}
1 & 0 & 0 \\
0 & 0 & -1 \\
0 & 1 & 0 \\
-1 & 0 & 0 \\
0 & 0 & 1 \\
0 & -1 & 0
\end{array}\right]\left[\begin{array}{l}
V_{A} \\
V_{B} \\
V_{C}
\end{array}\right]
$$

The major coils are denoted by the letters $A, B$, and $C$, whereas the subsidiary coils are denoted by the letters $a, b, c, d, e$, and $f$. The fundamental sum of the waveform's magnitude and angle serves as the mathematical foundation for this connection. Figure 2 depicts the phasor relationship between three-phase input voltages and six-phase output voltages in $60^{\circ}$ system.

Three-phase supply voltage equations are given by:

$$
\begin{gathered}
V_{A}=V_{m} \sin (\omega t) \\
V_{B}=V_{m} \sin \left(\omega t-120^{\circ}\right) \\
V_{C}=V_{m} \sin \left(\omega t-240^{\circ}\right)
\end{gathered}
$$

The output phase voltages of transformer $A$ are:

$$
\begin{gathered}
V_{a}=V_{m} \sin \left(\omega t-0^{\circ}\right) \\
V_{d}=V_{m} \sin \left(\omega t-180^{\circ}\right)
\end{gathered}
$$

The output phase voltages of transformer $B$ are given by:

$$
V_{c}=V_{m} \sin \left(\omega t-120^{\circ}\right)
$$




$$
V_{f}=V_{m} \sin \left(\omega t-120^{\circ}-180^{\circ}\right)=V_{m} \sin \left(\omega t-300^{\circ}\right)
$$

Finally, the output phase voltages of transformer $C$ are:

$$
\begin{gathered}
V_{e}=V_{m} \sin \left(\omega t-240^{\circ}\right) \\
V_{b}=V_{m} \sin \left(\omega t-240^{\circ}-180^{\circ}\right)=V_{m} \sin \left(\omega t-60^{\circ}\right)
\end{gathered}
$$

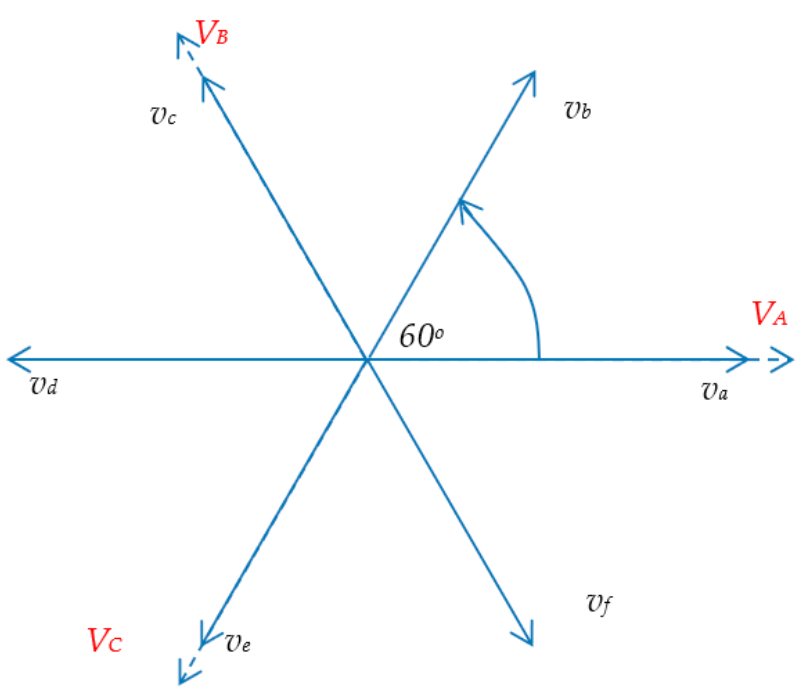

Figure 2. Phasor diagram of three and six-phase voltages.

\section{Modeling of Three-Phase Inverter}

A three-phase inverter with an appropriate pulse width modulation (PWM) approach may create a sinusoidal waveform by adjusting the $\mathrm{V} / \mathrm{F}$ ratio to regulate the induction motor speed. The three-phase PWM inverter is shown in Figure 3a [42-44]. The circuit of the three-phase PWM inverter is shown in Figure 3b.

The KVL equation of Figure 3 is presented as [15]:

$$
\left\{\begin{array}{l}
v_{a o}=v_{a n}+v_{n o} \\
v_{b o}=v_{b n}+v_{n o} \\
v_{c o}=v_{c n}+v_{n o}
\end{array}\right.
$$

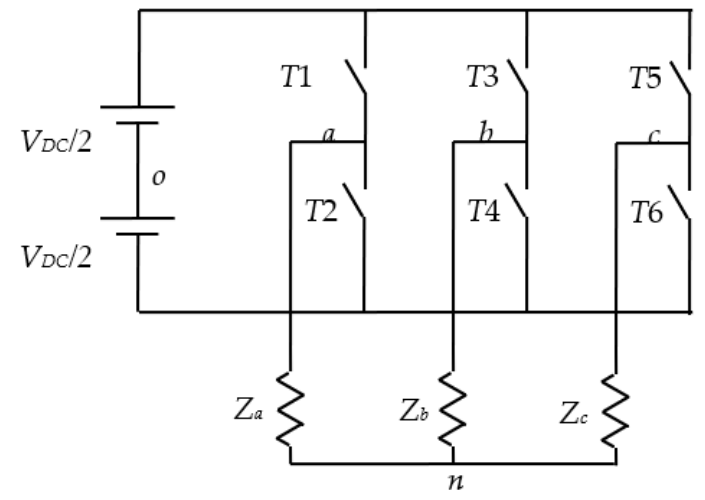

(a)

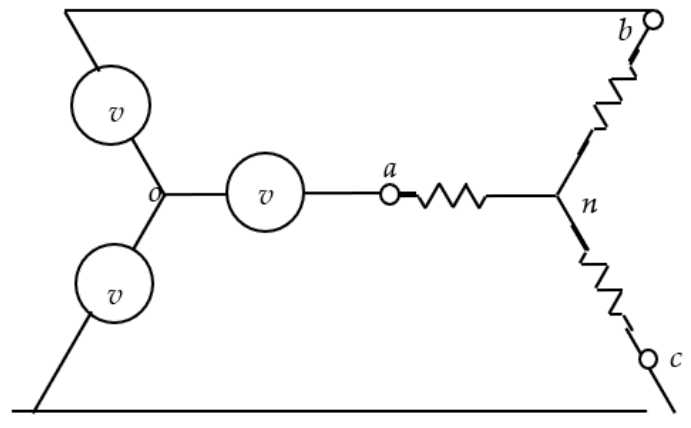

(b)

Figure 3. Three-phase inverter.(a) Primary three-phase inverter, (b) circuit of the three-phase inverter. 
Summing Equation (11) gives:

$$
v_{n o}=\frac{1}{3}\left(v_{a o}+v_{b o}+v_{c o}\right)
$$

Merging (11) and (12) leads to:

$$
\left[\begin{array}{l}
v_{a n} \\
v_{b n} \\
v_{c n}
\end{array}\right]=\frac{1}{3}\left[\begin{array}{ccc}
2 & -1 & -1 \\
-1 & 2 & -1 \\
-1 & -1 & 2
\end{array}\right]\left[\begin{array}{l}
v_{a o} \\
v_{b o} \\
v_{c o}
\end{array}\right]
$$

\section{Model of Six-Phase Induction Motor}

The six-phase squirrel cage induction motor winding consists of two three-phase groups, where $60^{\circ}$ electrical can be expressed as asymmetrical six-phase machine [45].

The symmetrical six-phase supply voltages of six-phase IM are expressed as [18,44]:

$$
\left\{\begin{array}{l}
v_{a s}=V_{m} \sin (\omega t) \\
v_{b s}=V_{m} \sin \left(\omega t-\frac{\pi}{3}\right) \\
v_{c s}=V_{m} \sin \left(\omega t-\frac{2 \pi}{3}\right) \\
v_{d s}=V_{m} \sin \left(\omega t-\frac{3 \pi}{3}\right) \\
v_{e s}=V_{m} \sin \left(\omega t-\frac{4 \pi}{3}\right) \\
v_{f s}=V_{m} \sin \left(\omega t-\frac{5 \pi}{3}\right)
\end{array}\right.
$$

The voltage d-q axis $V_{d}, V_{q}$ component can be reformulated as [46]:

$$
\begin{aligned}
& V_{q}=\frac{2}{6}\left[\sum_{k=1}^{6} v_{k} \cos \left(\theta-\frac{(k-1) \pi}{6}\right)\right] \\
& V_{d}=\frac{2}{6}\left[\sum_{k=1}^{6} v_{k} \sin \left(\theta-\frac{(k-1) \pi}{6}\right)\right]
\end{aligned}
$$

The q-axis of stator flux $\psi_{q s}$ and rotor flux $\psi_{q r}$ is represented as [15]:

$$
\begin{gathered}
\psi_{q s}=\frac{i}{s}\left[V_{q s}-\frac{R_{s}}{L_{s}}\left[\psi_{q s}-L_{m} i_{q r}\right]-\omega_{e} \psi_{d s}\right] \\
\psi_{q r}=\frac{i}{s}\left[-\frac{R_{r}}{L_{r}}\left[\psi_{q r}-L_{m} i_{q s}\right]+\left(\omega_{r}-\omega_{e}\right) \psi_{d r}\right]
\end{gathered}
$$

where $R s$ is the stator resistance, $R_{r}$ is the rotor resistance, $L_{m}$ magnetizing inductance, $L_{s}$ stator inductance, $L_{r}$ rotor inductance, $i_{q r} \mathrm{q}$-axis rotor current, $i_{q s} \mathrm{q}$-axis stator current, d-axis of rotor flux $\psi_{d r}$ and stator $\psi_{d s}$ flux is expressed as [40]:

$$
\begin{aligned}
& \psi_{d s}=\frac{1}{s}\left[V_{d s}-\frac{R_{s}}{L_{s}}\left[\psi_{d s}-L_{m} i_{d r}\right]+\omega_{e} \psi_{q s}\right] \\
& \psi_{d r}=\frac{1}{s}\left[\frac{R_{r}}{L_{r}}\left[\psi_{q r}-L_{m} i_{d s}\right]+\left(\omega_{e}-\omega_{r}\right) \psi_{q r}\right]
\end{aligned}
$$

where $i_{d r} \mathrm{~d}$-axis rotor current, $i_{d s} \mathrm{~d}$-axis stator current.

The developed torque $T_{e}$ and speed $\omega_{r}$ equations are obtained as [15]:

$$
\begin{gathered}
T_{e}=\frac{6}{2}\left[\frac{p}{2}\left[\psi_{d s} i_{q s}-\psi_{q s} i_{d s}\right]\right] \\
\omega_{r}=\frac{p}{2} \frac{1}{s}\left[\frac{1}{J}\left(T_{e}-T_{L}-B \frac{2}{p} \omega_{r}\right)\right]
\end{gathered}
$$




$$
n_{r}=\frac{2}{p} \frac{60}{2 \pi} \omega_{r}
$$

where $p$ is the number of poles, $T_{L}$ load torque, $J$ is the total moment of inertia, $B$ is the Friction coefficient, and $n_{r}$ is the mechanical speed.

The centrifugal pump model can be described by the relation between the head $H$ as a function of motor speed and pump discharge $Q$ [1].

$$
H=a_{0} \omega_{r}^{2}+a_{1} \omega_{r} Q+a_{2} Q^{2}
$$

where $a_{0}, a_{1}$, and $a_{2}$ are the pump head coefficient. The centrifugal pump torque $T p$ and hydraulic power $P_{h}$ can be calculated, respectively.

$$
\begin{gathered}
T_{p}=k_{r} \omega_{r}^{2}+T_{s} \\
P_{h}=Q \rho g H
\end{gathered}
$$

where $\rho$ is the fluid density, $g$ is the acceleration due to gravity, $k_{r}$ and $T_{s}$ are the pump torque constant.

\section{Proposed Control Strategy}

The speed control V/F closed-loop type is distinguished by its good accuracy and simplicity of tracking the reference speed [47-49]. The proposed PID control strategy is used to emulate a closed-loop controller to maintain the modified six phases IM following the reference speed. Figure 4 shows the schematic diagram of the proposed scalar control $(\mathrm{V} / \mathrm{F})$ system of a three-phase inverter fed to a three-to-six phase transformer loaded by the six-phase IM. The slip speed instruction is generated by the speed loop fault through the proportional-integral controller and limiter. The slip frequency $\omega^{*}$ instruction is created by adding the slip speed $\omega_{\mathrm{s}}{ }^{*}$ to the rotor speed. The voltage references are generated by the slip frequency references using a V/F calculation. The slip frequency $\omega^{*}$ is increased, resulting in a positive error, and the slip speed $\omega_{\mathrm{s}}{ }^{*}$ is adjusted to its maximum. The increase of slip frequency $\omega^{*}$ giving a positive error and slip speed $\omega_{\mathrm{s}}{ }^{*}$ is adjusted at its maximum. The motor accelerates at the maximum inverter current, delivering the maximum torque feasible, to reduce the speed error to minimum value. Finally, the inverter is steady on a slip speed where the load torques and motor torque are equal. The decrease of slip frequency $\omega^{*}$ giving a negative error and slip speed $\omega_{\mathrm{s}}^{*}$ is adjusted at its maximum negative. The motor decelerates at the maximum inverter current, delivering the maximum braking torque feasible, to reduce the speed error to minimum value. Finally, the inverter is steady on a slip speed where the load torques and motor torque are equals.

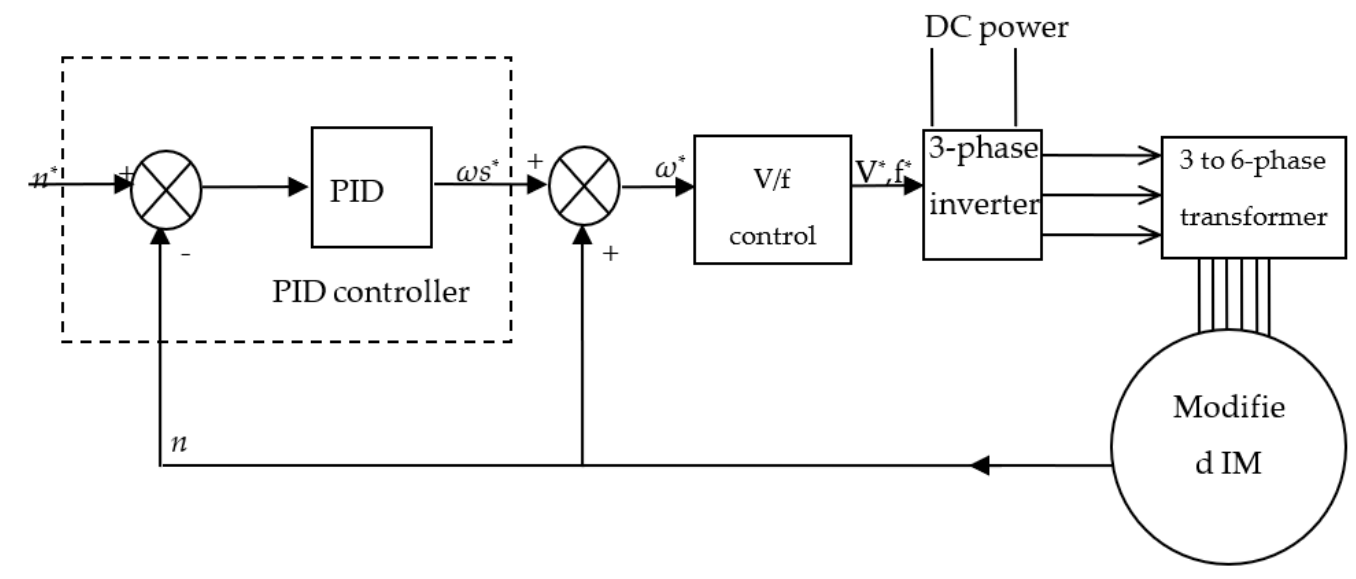

Figure 4. The PID schematic diagram of modified six-phase induction motor control. 


\section{Implementation of Six-Phase Induction Motor}

\subsection{Experimental Setup}

The system under study is composed of six main interacting components, as shown in Figure 5.

(1) Control board stage (three-phase inverter).

(2) Power stage.

(3) Design and implementation of $3300 \mathrm{VA}, 220 / 220 \mathrm{~V}$, prototype three-to-six phase transformer [41].

(4) A3-hp, $380 \mathrm{~V}$, 2-pole three-phase IM prototype modified six-phase induction motor [41].

(5) Measuring instruments.

(6) Electrical break (centrifugal pumping load).

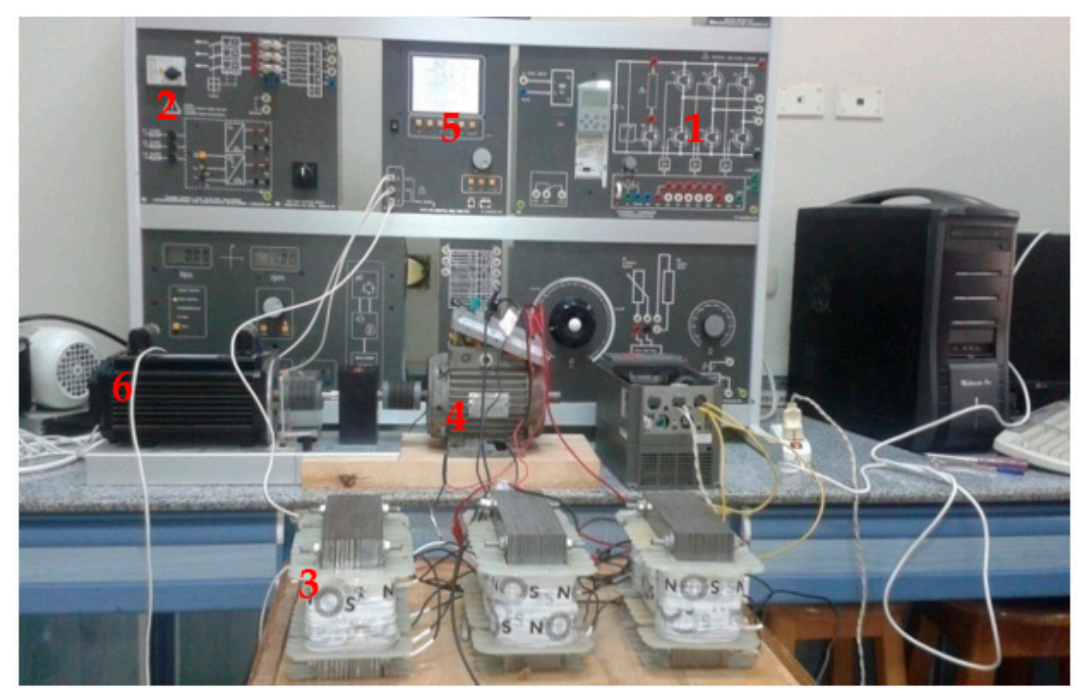

Figure 5. Block diagram of the experimental setup located in the Electrical Power Laboratory in the Faculty of Engineering, Electrical Engineering Department, Kafrelshiekh University.

\subsection{Studied Cases}

To investigate the proposed constant V/F speed (scalar) control method, the whole drive system was simulated using Matlab/Simulink package. The results were compared with experimental measurements obtained using a laboratory setup. Five cases were proposed to simulate the different operating conditions as shown in Table 1 . The threeto-six phase transformer rated values are given in Table 2. The parameters of modified six-phase IM are given in Table 3. The speed is achieved with the hand-tuning of the PID controller.

Table 1. Studied cases.

\begin{tabular}{cccc}
\hline \multirow{2}{*}{ Period No. } & \multicolumn{2}{c}{ Period (min.) } & Description \\
\cline { 2 - 3 } & From & To & Starting instant \\
\hline 1 & 0 & 0.35 & Rated operation $(2800 \mathrm{rpm})$ \\
\hline 2 & 0.35 & 1 & Low-speed operation $(2000 \mathrm{rpm})$ \\
\hline 3 & 1 & 2 & More speed reduction $(1000 \mathrm{rpm})$ \\
\hline 4 & 2 & 3 & Rated operating period $(2800 \mathrm{rpm})$ \\
\hline 5 & 3 & 4 &
\end{tabular}


Table 2. The proposed transformer test reading.

\begin{tabular}{cccc}
\hline Values & Reading & Values & Reading \\
\hline$V_{\text {in }}(\mathrm{V})$ & 220 & $V_{o 1}(\mathrm{~V})$ & 220 \\
\hline$V_{o 2}(\mathrm{~V})$ & 220 & $\mathrm{I}(\mathrm{A})$ & 5 \\
\hline
\end{tabular}

Table 3. Six-phase induction motor parameters.

\begin{tabular}{cccc}
\hline Parameter & Value & Parameter & Value \\
\hline$L_{l s}(H)$ & 0.0409 & $R_{r}(\Omega)$ & 8.097 \\
\hline$L_{m}(H)$ & 0.849 & $J\left(\mathrm{~kg} \cdot \mathrm{m}^{2}\right)$ & 0.003 \\
\hline$L_{l r}(H)$ & 0.0409 & $p(\mathrm{poles})$ & 2 \\
\hline$R_{s} \Omega$ & 12 & $V_{p h}(\mathrm{~V})$ & 220 \\
\hline
\end{tabular}

\subsection{Simulation and Experimental Results}

Figures 6-12 show the simulation results of the system under study. There are two studies cases; the first case is the operation from a three-phase inverter and three-to-six phase transformer (TITST), the second case is the operation using a six-phase inverter (SI). Figure 6 shows the speed variation for both cases with PID $\left(k_{p}=0.7, k_{i}=0.15, k_{d}=0.02\right)$. This figure clearly shows the difference between the two cases in the response of the motor speed to the changes that follow the reference speed, and this clearly shows in the fourth period, where a decrease in speed occurs for the operating system with SI up to $240 \mathrm{rpm}$, while in the proposed system it does not exceed $8 \mathrm{rpm}$.

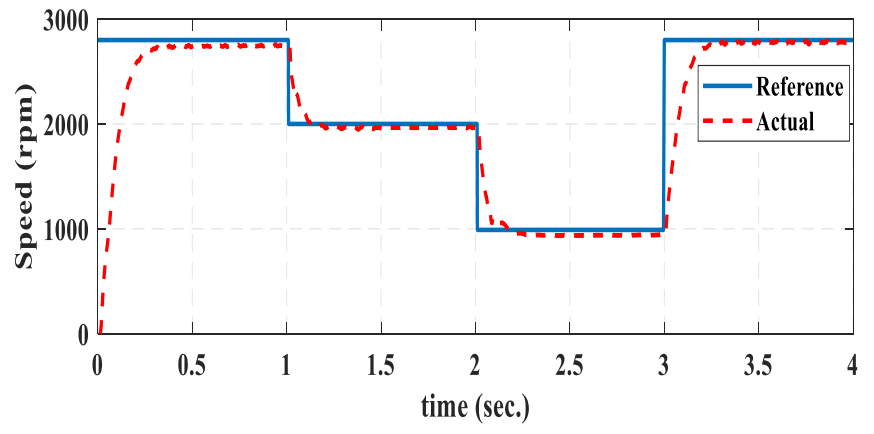

(a)

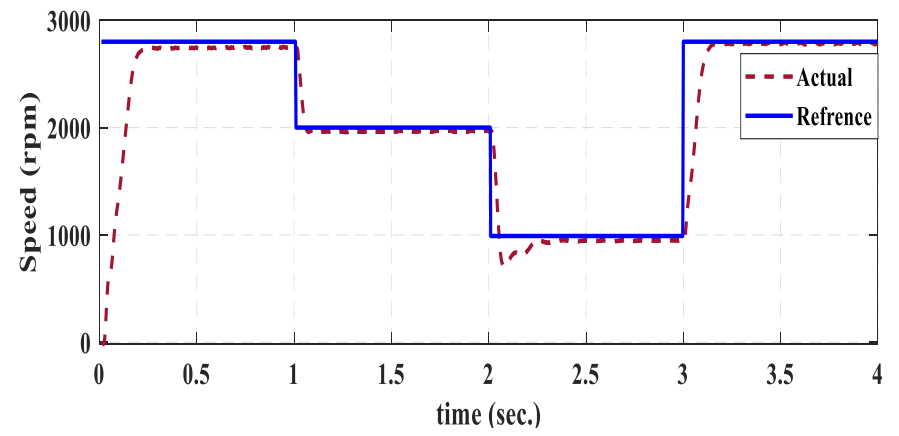

(b)

Figure 6. Speed-time characteristics: (a) with 3-phase inverter and transformer, (b) with 6-phase inverter.

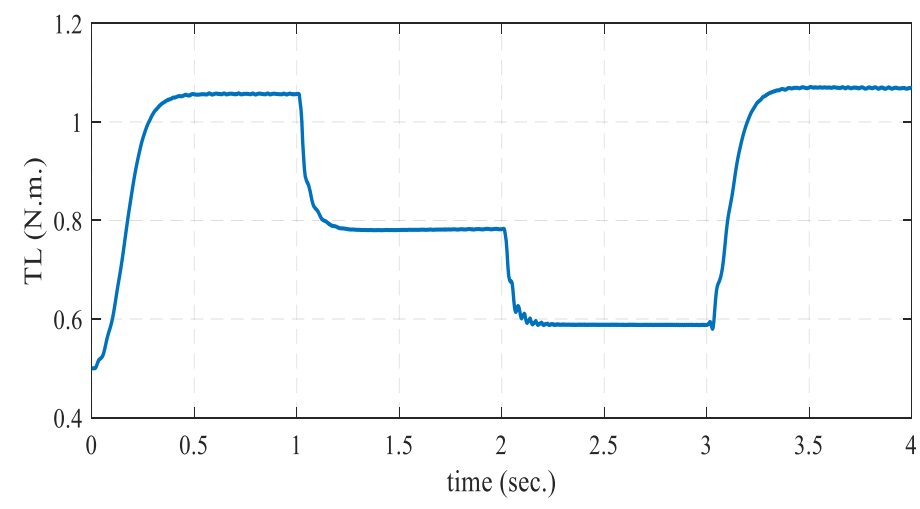

Figure 7. Pump torque-time characteristics with PID. 


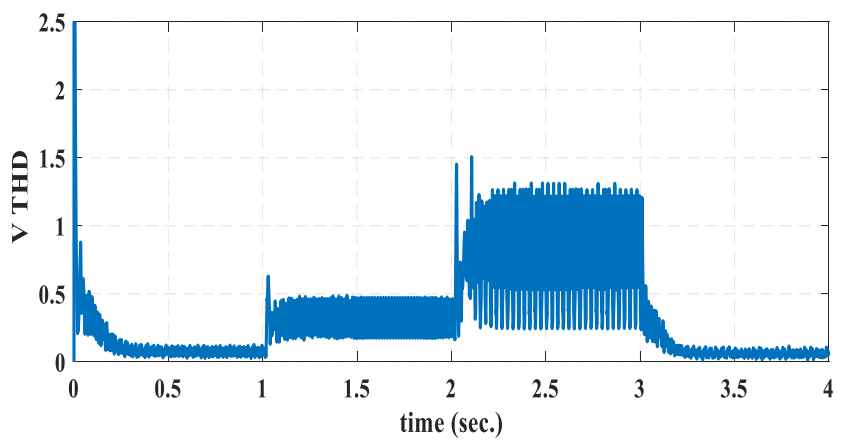

(a)

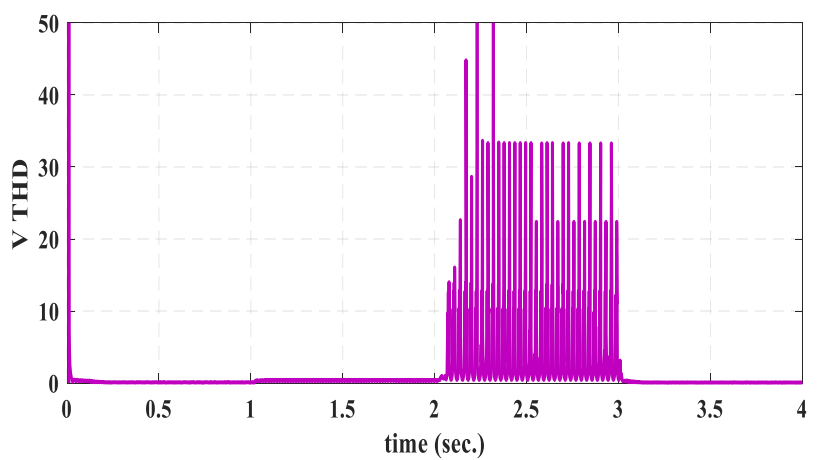

(b)

Figure 8. THD in voltage-time characteristics: (a) with 3-phase inverter and transformer(b) with 6-phase inverter.

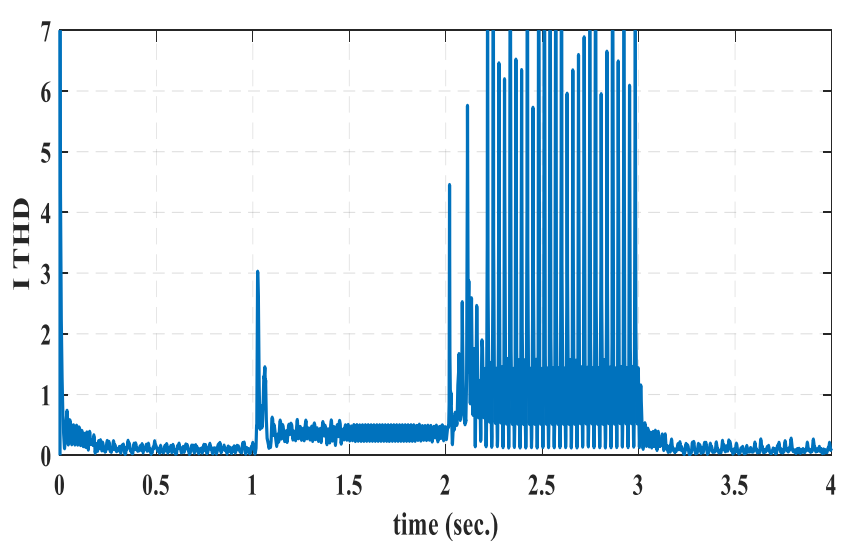

(a)

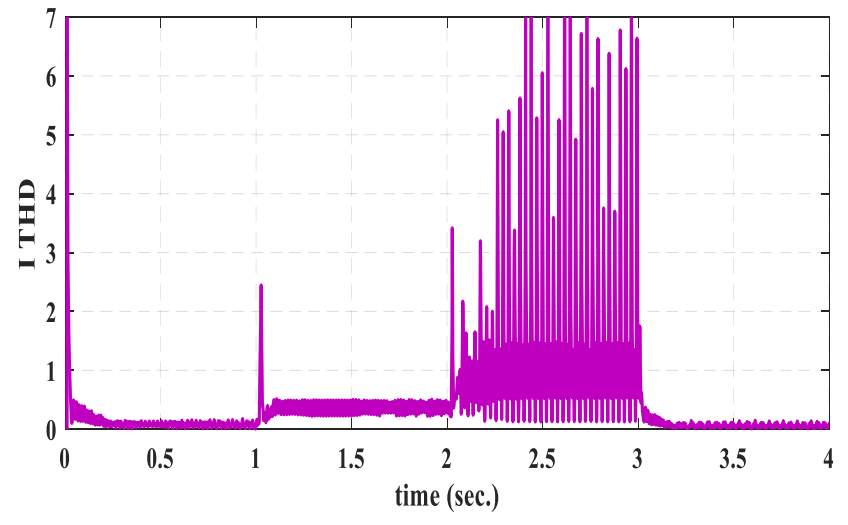

(b)

Figure 9. THD in current-time characteristics: (a) 3-phase inverter and transformer, (b) with 6-phase inverter.

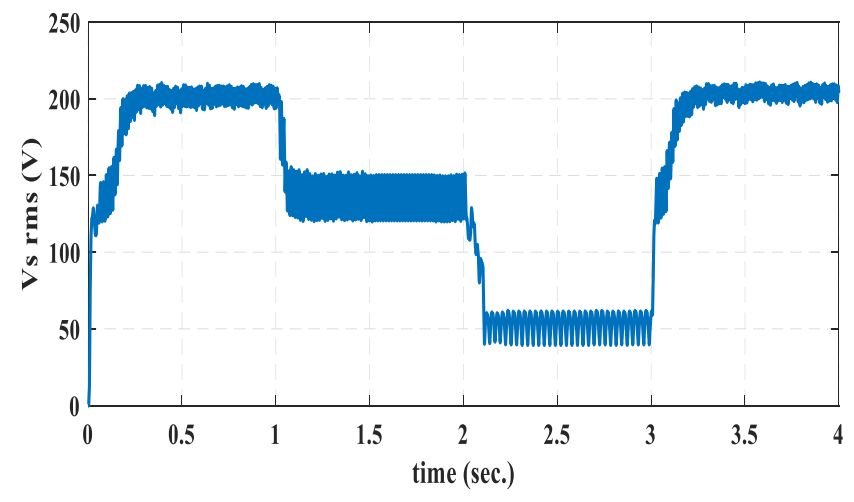

(a)

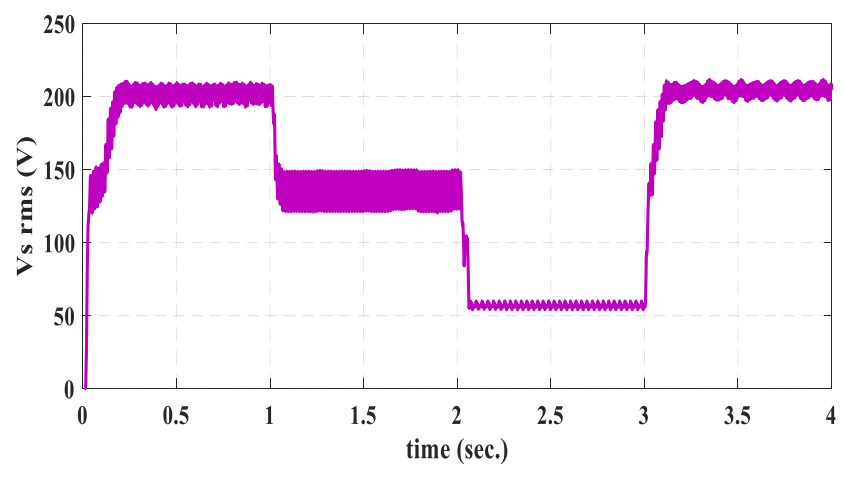

(b)

Figure 10. Stator voltage-time response: (a) with 3-phase inverter and transformer, (b) with 6-phase inverter. 


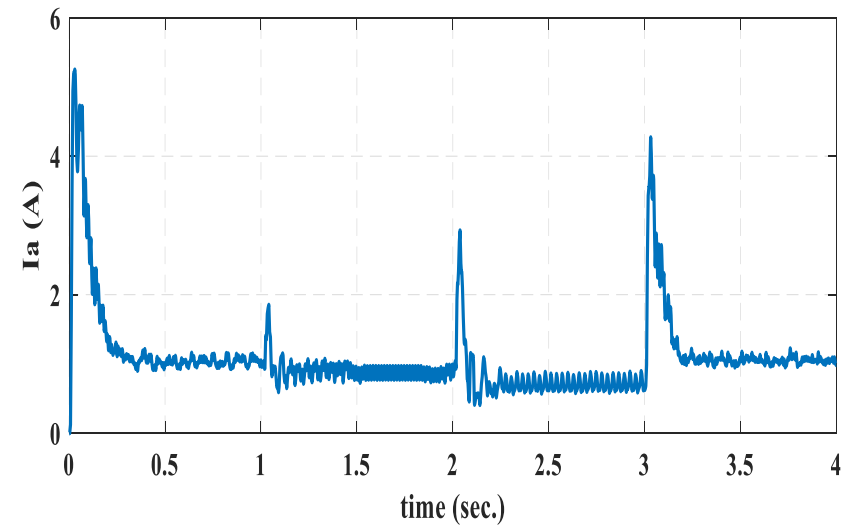

(a)

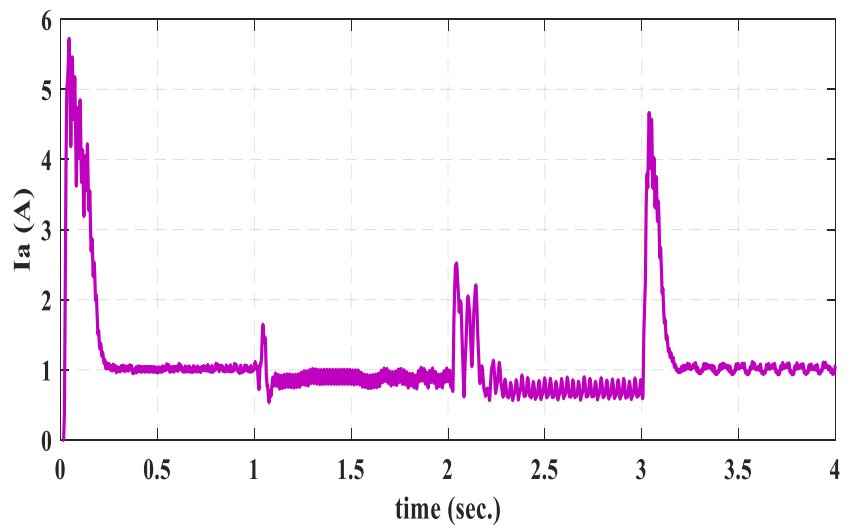

(b)

Figure 11. Stator phase current-time response: (a) with 3-phase inverter and transformer, (b) with 6-phase inverter.

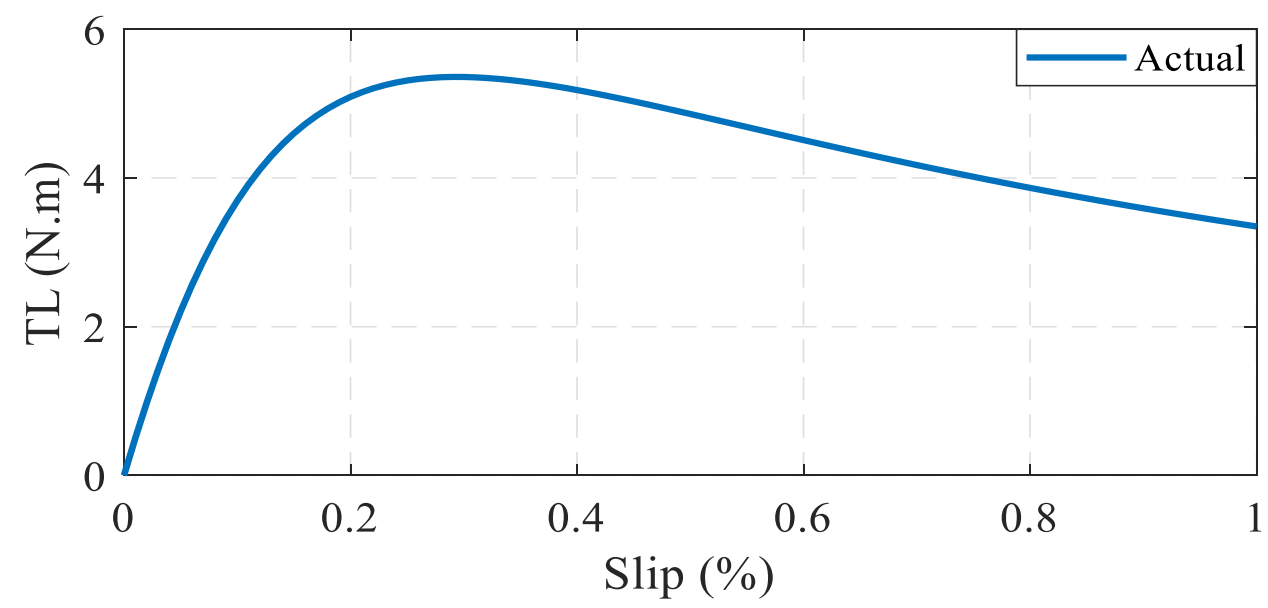

Figure 12. Torque-slip characteristics of the adapted six-phase induction motor.

The speed performance for both cases is close to the reference speed. The proposed case performed better in terms of rise time, overshoot, and steady-state error. Figure 7 shows the simulation centrifugal pump torque of the five studied periods. The closed-loop method has been validated for determining the required motor speed. The speed is very close to the actual value, while at the lower speed in the transient period, the speed is firstly oscillated and goes to steady speed with no oscillation.

Figures 8 and 9 show the simulation of harmonic contents of voltage and current total harmonic distortion THD, respectively. The operation using TITST is better and gives a smaller value of total harmonic distortion. Figure 10 represents the phase voltage of different periods of operation for the two cases.

Figure 11 clearly shows that the simulation of stator current in the proposed system increases to $5.2 \mathrm{~A}$, while it increases to $5.72 \mathrm{~A}$ in the classic system; this means that using a three-to-six phase transformer reduces starting current by $6.7 \%$. In the second period, the mean value is reduced to its rated value; these figures show that the TITST operation reduces oscillation value, particularly in low-speed operation.

Figure 12 shows the torque slip characteristics of the six-phase induction motor, which has a starting torque of 3.45 N.m. and maximum torque of 5.36 N.m. and the slip at maximum torque is 0.29 .

The results shown in Tables 4 and 5 validate the superiority of the TITST operation over the operation using SI; the steady-state error in the case of using a transformer integrated with a three-phase inverter in full speed period is $30 \mathrm{rpm}$ while in the case of the six-phase inverter is $55 \mathrm{rpm}$. The starting current in the case of using a transformer integrated with a 
three-phase inverter in full speed period is $5.2 \mathrm{~A}$ while in the case of the six-phase inverter is $5.72 \mathrm{~A}$. This means that the starting current is reduced by $9 \%$, while the value of THD content in stator voltage of TITST is 0.8 compared to $3 \%$ in the case of using SI. It means that this proposed system will improve the voltage and speed profiles.

Table 4. Assessment of speed to TITST against SI controllers.

\begin{tabular}{cccc}
\hline \multirow{2}{*}{ Period } & \multicolumn{1}{c}{ Speed (rpm) } \\
\cline { 2 - 4 } & State & TITST & SI \\
\cline { 2 - 4 } 1 & Steady state error & 30 & 55 \\
\cline { 2 - 4 } & Oscillation range & 25 & 25 \\
\hline \multirow{2}{*}{2} & Steady state error & 35 & 35 \\
\cline { 2 - 4 } & Oscillation range & 30 & 25 \\
\hline \multirow{2}{*}{3} & Steady state error & 50 & 55 \\
\cline { 2 - 4 } & Oscillation range & 8 & 240 \\
\hline \multirow{2}{*}{4} & Steady state error & 20 & 25 \\
\cline { 2 - 4 } & Oscillation range & 35 & 20 \\
\hline
\end{tabular}

Table 5. Assessment of current, THD in current, and THD voltage to TITST against SI controllers.

\begin{tabular}{cccccccc}
\hline \multirow{2}{*}{ Period } & \multirow{2}{*}{ State } & \multicolumn{2}{c}{ Current (A) } & \multicolumn{2}{c}{ THD (\%) of Current } & \multicolumn{2}{c}{ THD (\%) of Voltage } \\
\cline { 2 - 8 } & & TITST & SI & TITST & SI & TITST & SI \\
\hline \multirow{3}{*}{1} & Starting value & 5.2 & 5.72 & 7 & 7 & 0.8 & 3 \\
\cline { 2 - 8 } & Oscillation range & 0.3 & 1.45 & 0.1 & 0.1 & 0.08 & 0.1 \\
\cline { 2 - 8 } & Mean & 1.05 & 1.02 & 0.55 & 0.5 & 0.11 & 0.2 \\
\hline \multirow{3}{*}{2} & Starting value & 1.85 & 1.65 & 3 & 2.5 & 0.62 & 0.45 \\
\cline { 2 - 8 } & Oscillation range & 0.55 & 0.5 & 0.38 & 0.4 & 0.35 & 0.35 \\
\cline { 2 - 8 } & Mean & 0.85 & 0.9 & 0.4 & 0.35 & 0.3 & 0.2 \\
\hline \multirow{3}{*}{3} & Starting value & 2.92 & 2.52 & 0.41 & 0.35 & 1.4 & 35 \\
\cline { 2 - 8 } & Oscillation range & 0.7 & 1.5 & 1 & 1 & 0.8 & 6 \\
\hline \multirow{nyyyyyyy}{*}{4} & Mean & 0.7 & 0.7 & 7 & 7 & 1 & 35 \\
\cline { 2 - 8 } & Starting value & 4.27 & 4.66 & 1.3 & 2 & 0.5 & 3 \\
\cline { 2 - 8 } & Oscillation range & 0.3 & 0.2 & 0.5 & 0.7 & 0.06 & 0.8 \\
\cline { 2 - 8 } & Mean & 1.05 & 1.05 & 0.35 & 0.35 & 0.09 & 0.1 \\
\hline \multirow{2}{*}{} & & & & & & & \\
\hline
\end{tabular}

Figures 13-17 show the experimental reading of the system under study using the electrical break as a centrifugal pump. Figure 13 shows the experimental relationship between voltage and frequency, in the range of $64.3-156$ volts, that corresponds to $20-50 \mathrm{~Hz}$ frequency variation. Figures 14 and 15 show the inverter frequency's experimental value of stator input current, and rotor speed changes.

Figures 16 and 17 show simulation and experimental load torque values and input current as rotor speed changes. These figures indicate that the simulated values are wellmatched and agree with their measured values. On the other hand, the small difference between the simulation values and the experimental results is owed to the consideration that the simulation of the system under study is assumed to be accurate at all operating ranges. The error between the measured and calculated values of mechanical torque ranges from 2.4 to $12.4 \%$, while the error between the measured and calculated values of the stator current ranges from 2.3 to $6.3 \%$, which indicates a convergence between the proposed practical model and the equivalent mathematical model. 


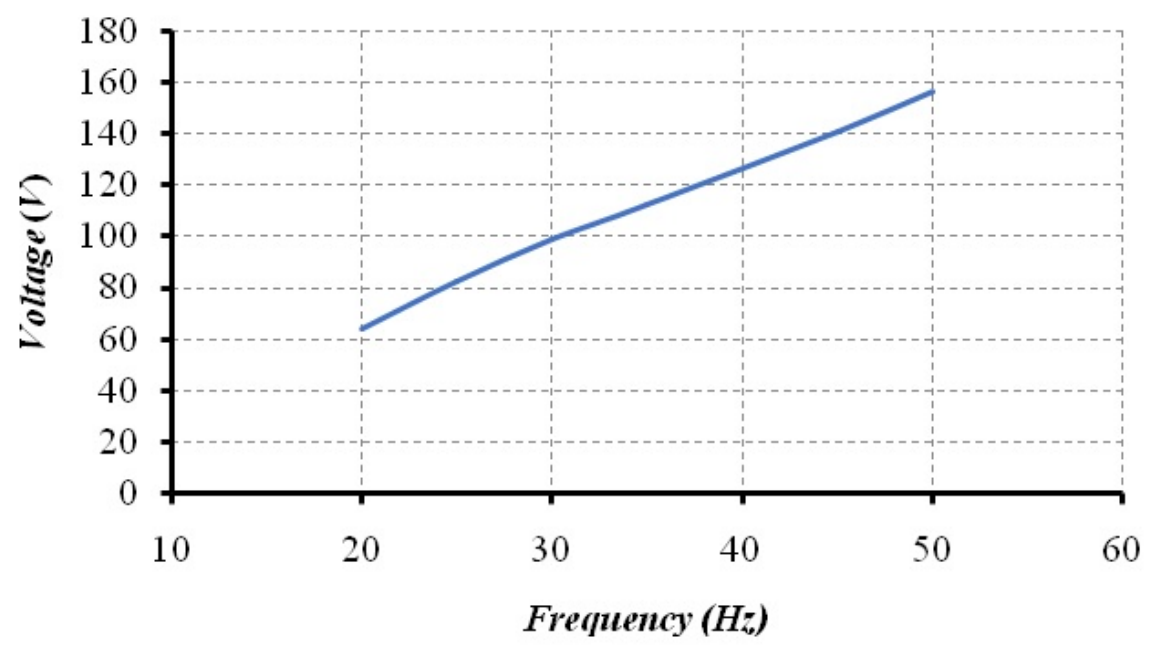

Figure 13. Measured motor voltage against frequency relationship.

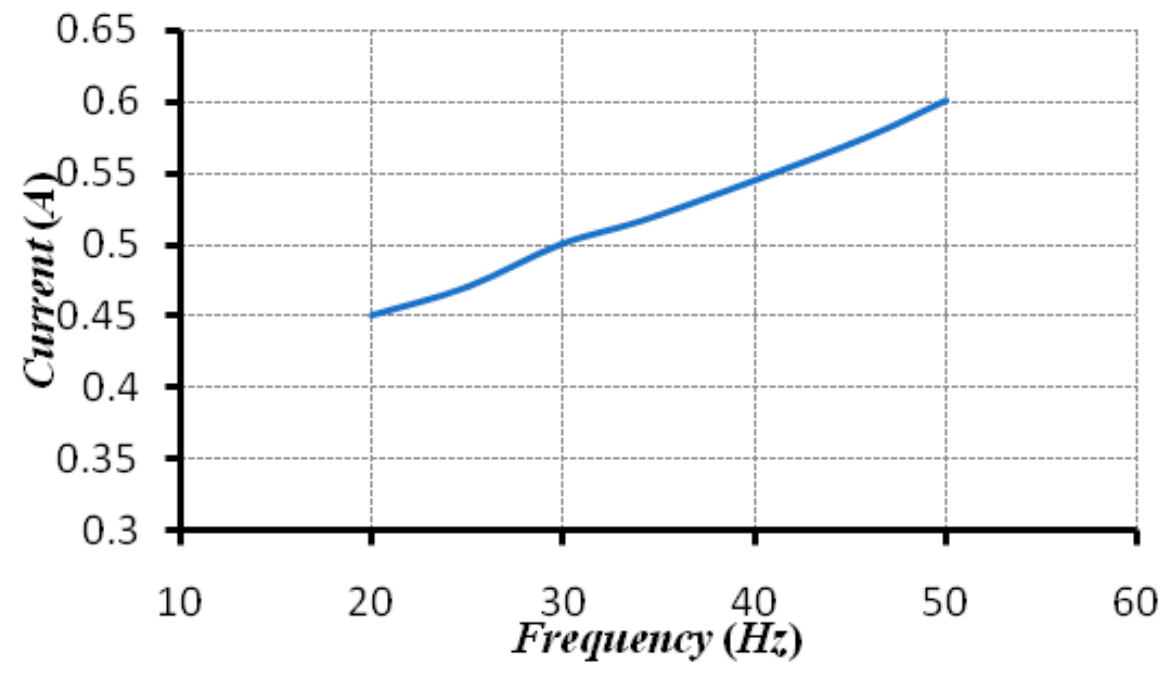

Figure 14. Measured input current against frequency relationship.

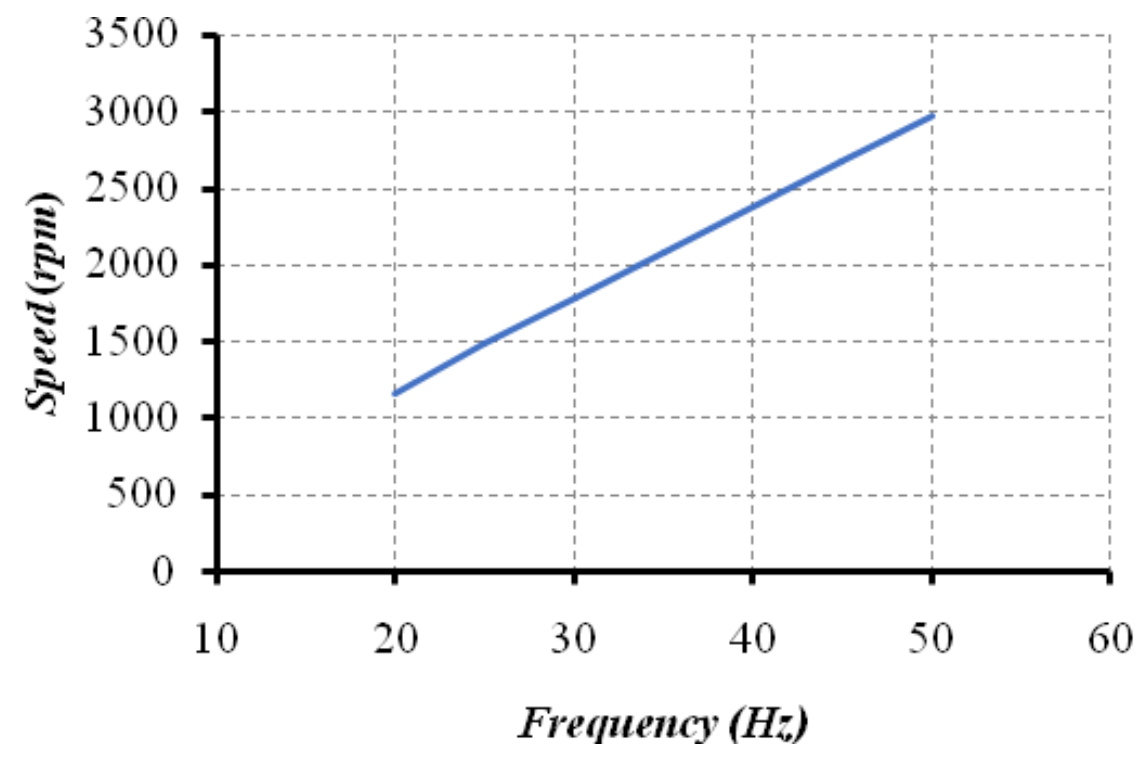

Figure 15. Measured rotor speed against frequency relationship. 


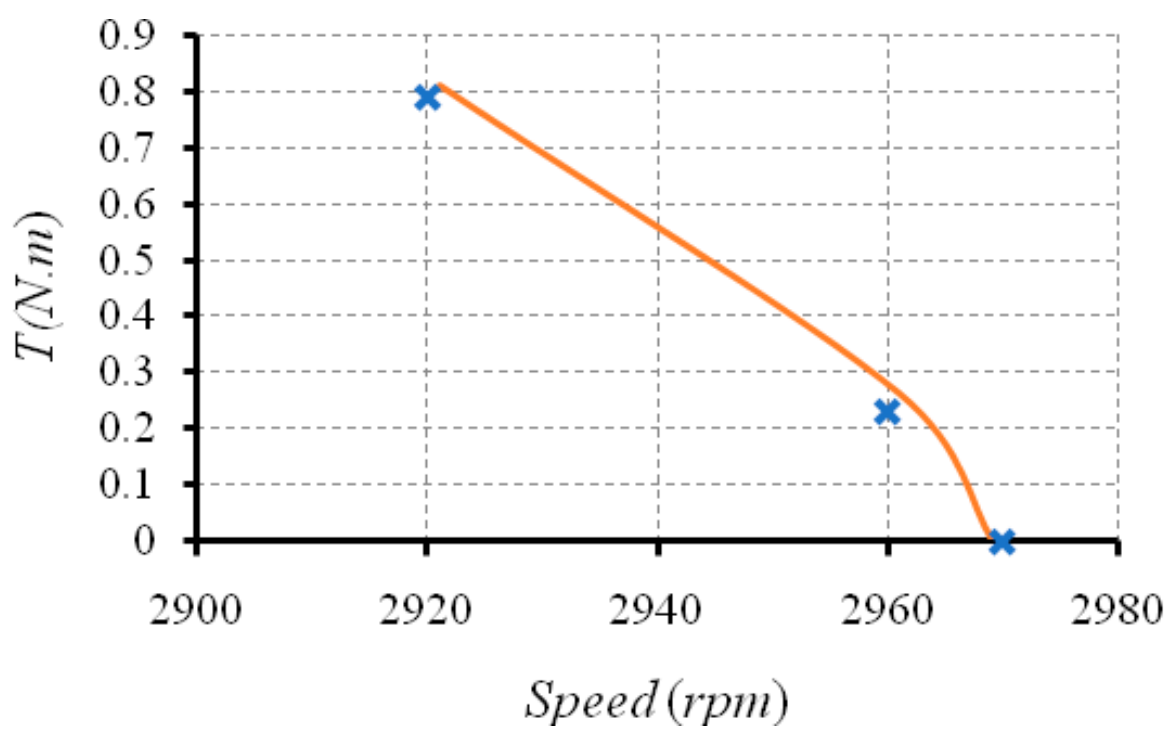

Figure 16. Torque-speed characteristics of six-phase motor (- simulation, x experimental).

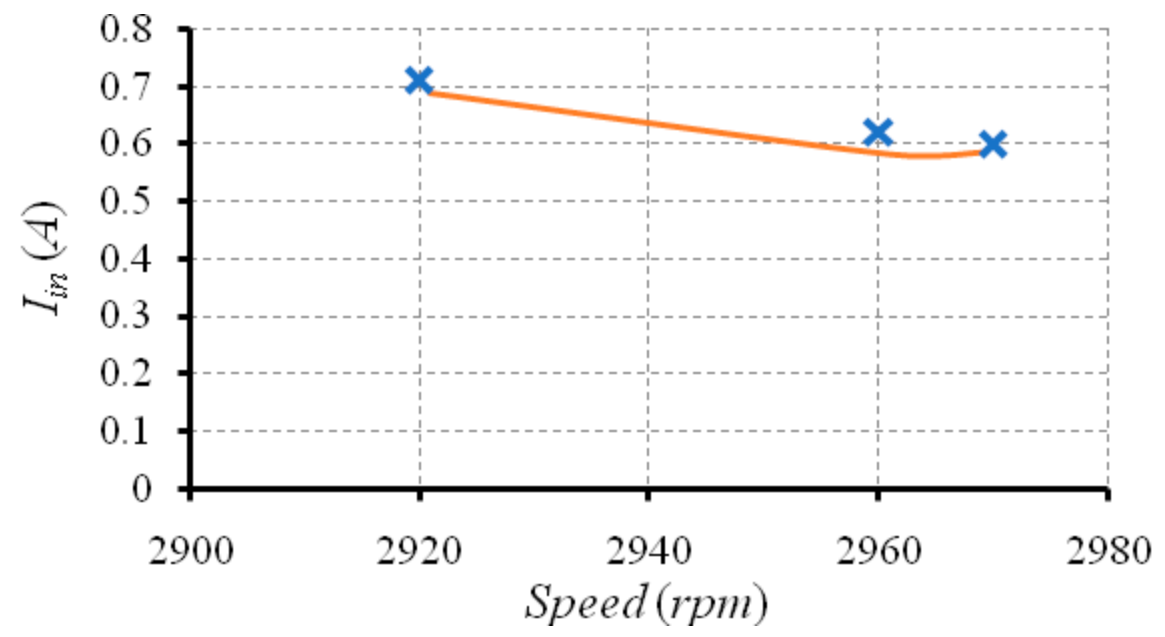

Figure 17. Current-speed characteristics of six-phase motor (- simulation, $x$ experimental).

\section{Conclusions}

This article presented the itemized analysis and implementation of the modified threephase IM to work as a six-phase IM that drives from a three-phase inverter through a three-to-six phase transformer. Design and implementation of three single-phase primary and two secondaries were connected to work as a six-phase transformer. A trial and error tuning PID achieved with a V/F (scalar) control used for speed control and a six-phase IM was analyzed, and its results of simulation were discussed. The simulation results show that the operation using a three-phase inverter connected with a three-to-six phase transformer was better than a six-phase inverter under the same conditions. An experimental setup of a modified three-phase IM to obtain the six-phase IM and its drive controlled by a three-phase inverter was tested. In this paper, a three-phase inverter was used to drive a six-phase induction motor through an electrical transformer to convert from three phases to six phases. The error between the measured and calculated values of mechanical torque lies between 2.4 and $12.4 \%$, while the error between the measured and calculated values of the stator current lies between 2.3 and $6.3 \%$, which indicates a convergence between the proposed practical model and the equivalent mathematical model. The quality of the output voltage and speed are improved, reduced harmonic contents with this proposed system, as shown in the speed and voltage profiles. The transformer of the proposed 
system also operated as an isolation device between the motor and the electrical source, and it allows direct operation from the traditional source. By comparing the cost between the classic system and the proposed system, the cost decreased using the proposed system by a value not less than $12.88 \%$.

Author Contributions: M.I.A., I.B.M.T., F.F.S. conceived and designed the experiments; M.I.A. performed the experiments, analyzed the data, contributed materials/analysis tools, established and validated the models and wrote the paper. M.I.A.; E.M.R., I.B.M.T., F.F.S. provided ideas for the discussion; M.I.A., E.M.R., I.B.M.T., F.F.S. reviewed the article. All authors have read and agreed to the published version of the manuscript.

Funding: Taif University Researchers Supporting Project Number (TURSP-2020/61), Taif University, Taif, Saudi Arabia.

Acknowledgments: The authors would like to acknowledge the financial support received from Taif University Researchers Supporting Project Number (TURSP-2020/61), Taif University, Taif, Saudi Arabia.

Conflicts of Interest: The authors declare no conflict of interest.

\section{References}

1. Abdelwanis, M.I.; Selim, F. A sensorless six-phase induction motor driving a centrifugal pump system. In Proceedings of the 19th International Middle-East Power Systems Conference, MEPCON 2017, Cairo, Egypt, 19-21 December 2017.

2. Nanoty, P.A.; Chudasama, P.A.R. Testing of Designed Developed Prototype Six Phase Induction Motor and Analysis of Problems Faced in Actual Development. IOSR J. 2014, 2014, 1-6.

3. Taheri, A.; Rahmati, A.; Kaboli, S. Comparison of efficiency for different switching tables in six-phase induction motor DTC drive. J. Power Electron. 2012, 12, 128-135. [CrossRef]

4. Nanoty, A.; Chudasama, A.R. Design, Development of Six Phase Squirrel Cage Induction Motor and its Comparative Analysis with Equivalent Three Phase Squirrel Cage Induction Motor Using Circle Diagram. Int. J. Emerg. Technol. Adv. Eng. 2013, 3, 731-737.

5. Singh, G.K. Multi-phase induction machine drive research-A survey. Electr. Power Syst. Res. 2002, 61, 139-147. [CrossRef]

6. Paredes, J.; Prieto, B.; Satrústegui, M.; Elósegui, I.; González, P. Improving the Performance of a 1-MW Induction Machine by Optimally Shifting from a Three-Phase to a Six-Phase Machine Design by Rearranging the Coil Connections. IEEE Trans. Ind. Electron. 2021, 68, 1035-1045. [CrossRef]

7. Heidari, H.; Rassõlkin, A.; Vaimann, T.; Kallaste, A.; Taheri, A.; Holakooie, M.H.; Belahcen, A. A novel vector control strategy for a six-phase induction motor with low torque ripples and harmonic currents. Energies 2019, 12, 1102. [CrossRef]

8. Huang, J.; Kang, M.; Yang, J.Q.; Jiang, H.B.; Liu, D. Multiphase machine theory and its applications. In Proceedings of the 2008 International Conference on Electrical Machines and Systems, Wuhan, China, 17-20 October 2008; pp. 1-7.

9. Singh, G.K.; Pant, V. Analysis of a multiphase induction machine under fault condition in a phase-redundant A.C. drive system. Electr. Mach. Power Syst. 2000, 28, 577-590. [CrossRef]

10. Abdel-Khalik, A.S.; Abdel-Majeed, M.S.; Ahmed, S. Effect of Winding Configuration on Six-Phase Induction Machine Parameters and Performance. IEEE Access 2020, 8, 223009-223020. [CrossRef]

11. Mandal, S. Performance Analysis of Six-Phase Induction Motor. Int. J. Eng. Res. Technol. 2015, 4, 589-593.

12. Nagaraj, P.; Kannan, V.; Santhi, M. Modified Multiphase Induction Motor with High Starting Torque. Int. J. Innov. Res. Sci. Eng. Technol. 2014, 3, 519-522.

13. Ai, Y.; Wang, Y.; Kamper, M.J. Torque performance comparison from three-phase with six-phase induction machine. In Proceedings of the 2009 International Conference on Mechatronics and Automation, Changchun, China, 9-12 August 2009; pp. 1417-1421.

14. Renukadevi, G.; Rajambal, K. Generalized d-q Model of n-Phase Induction Motor. Int. J. Electr. Comput. Eng. 2012, 6, 1066-1075.

15. Abdelwanis, M.I.; El-Sehiemy, R.A. A Fuzzy-Based Controller of a Modified Six-Phase Induction Motor Driving a Pumping System. Iran. J. Sci. Technol.-Trans. Electr. Eng. 2019. [CrossRef]

16. Okpo, E.E.; Okoro, O.I.; Awah, C.C.; Akuru, U.B. Performance Evaluation of 5.5 kW Six-Phase Asynchronous Motor. In Proceedings of the 2019 IEEE PES/IAS PowerAfrica, Abuja, Nigeria, 20-23 August 2019; pp. 639-644.

17. Lyra, R.O.C. Torque density improvement in a six-phase induction motor with third harmonic current injection. IEEE Trans. Ind. Appl. 2002, 38, 1351-1360. [CrossRef]

18. Nanoty, A.R.; Chudasama, A. Control of Designed Developed Six Phase Induction Motor. Int. J. Electromagn. Appl. 2012, 2, 77-84. [CrossRef]

19. Bachir, G.; Bendiabdellah, A. Scalar control for six phase matrix converter fed double star induction motor. Adv. Electr. Comput. Eng. 2010, 10, 121-126. [CrossRef]

20. Nabi, H.P.; Dadashi, P.; Shoulaie, A. A novel structure for vector control of a symmetrical six-phase induction machine with three current sensors. In Proceedings of the 2011 10th International Conference on Environment and Electrical Engineering, Rome, Italy, 8-11 May 2011; pp. 1-5. 
21. Maia, A.C.N.; Jacobina, C.B. Six-phase machine drive system based on three three-leg converters. In Proceedings of the 2013 Brazilian Power Electronics Conference, Gramado, Brazil, 27-31 October 2013; pp. 915-920.

22. Kali, Y.; Saad, M.; Doval-Gandoy, J.; Rodas, J. Discrete Terminal Super-Twisting Current Control of a Six-Phase Induction Motor. Energies 2021, 14, 1339. [CrossRef]

23. Alam, M.S.; Khan, M.R.; Kumar, A. Stability analysis of a five phase closed loop induction motor drive system using D-Partition technique. In Proceedings of the 2016 International Conference on Electrical, Electronics, and Optimization Techniques (ICEEOT), Chennai, India, 3-5 March 2016; pp. 1298-1302.

24. Wu, D.; Chang, C.S.; Fang, Y.; Bai, H. Performance improvement of V/f induction -motor control in the low-frequency range. In Proceedings of the 8th International Conference on Advances in Power System Control, Operation and Management (APSCOM 2009), Hong Kong, China, 8-11 November 2009; pp. 1-6.

25. Itoh, J.I.; Nakajima, Y.; Kato, M. Maximum torque per ampere control method for IPM Synchronous Motor based on V/f control. In Proceedings of the 2013 IEEE 10th International Conference on Power Electronics and Drive Systems (PEDS), Kitakyushu, Japan, 22-25 April 2013; pp. 1322-1327. [CrossRef]

26. Agarlita, S.C.; Coman, C.E.; Andreescu, G.D.; Boldea, I. Stable V/f control system with controlled power factor angle for permanent magnet synchronous motor drives. IET Electr. Power Appl. 2013, 7, 278-286. [CrossRef]

27. Padmanaban, S.; Grandi, G.; Blaabjerg, F.; Olorunfemi Ojo, J.; Wheeler, P.W. Power sharing algorithm for vector controlled six-phase AC motor with four customary three-phase voltage source inverter drive. Eng. Sci. Technol. Int. J. 2015, 18, 408-415. [CrossRef]

28. Abdelwanis, M.I.; Selim, F.; El-Sehiemy, R.A. An efficient sensorless slip dependent thermal motor protection schemes applied to submersible pumps. Int. J. Eng. Res. Afr. 2015. [CrossRef]

29. Abd-Elwanis, M.I.; Selim, F.F. A Sensorless Controller of Submersible Motors Fed From Photovoltaic System. In Proceedings of the 17th International Middle-East Power System Conference, Mansoura, Egypt, 15-17 December 2015.

30. Taheri, A.; Ren, H.P.; Holakooie, M.H. Sensorless Loss Model Control of the Six-Phase Induction Motor in All Speed Range by Extended Kalman Filter. IEEE Access 2020, 8, 118741-118750. [CrossRef]

31. Shawier, A.; Habib, A.; Mamdouh, M.; Abdel-Khalik, A.S.; Ahmed, K.H. Assessment of Predictive Current Control of Six-Phase Induction Motor with Different Winding Configurations. IEEE Access 2021, 9, 81125-81138. [CrossRef]

32. Levi, E.; Bojoi, R.; Profumo, F.; Toliyat, H.A.; Williamson, S. Multiphase induction motor drives-a technology status review. IET Electr. Power Appl. 2007, 1, 643-656. [CrossRef]

33. Aziz, G.A.A.; Amin, M.; El-Sousy, F.F.M.; Gaber, K. MRAS-based Super-Twisting Sliding-Mode Observer with DTC of Six-Phase Induction Motor for Ship Propulsion Application. In Proceedings of the 2020 IEEE Industry Applications Society Annual Meeting, Detroit, MI, USA, 3-4 March 2020; pp. 1-7.

34. Daoud, M.I.; Massoud, A.; Abdel-Khalik, A.; Ahmed, S. An asymmetrical six-phase induction machine-based flywheel energy storage system using modular multilevel converters. In Proceedings of the 19th International Conference on Electrical Machines and Systems, Chiba, Japan, 13-16 November 2017; pp. 1-6.

35. Abdelwanis, M.I.; Abaza, A.; El-Sehiemy, R.A.; Ibrahim, M.N.; Rezk, H. Parameter Estimation of Electric Power Transformers Using Coyote Optimization Algorithm with Experimental Verification. IEEE Access. 2020, 8, 1-9. [CrossRef]

36. Chen, X. Three-phase/six-phase conversion autotransformers. IEEE Trans. Power Deliv. 2003, 18, 1554-1561. [CrossRef]

37. Al-Ammari, R.; Iqbal, A.; Khandakar, A.; Rahman, S.; Padmanaban, S. Systematic implementation of multi-phase power supply (Three to six) conversion system. Electron 2019, 8, 109. [CrossRef]

38. Iqbal, A.; Moinuddin, S.; Khan, M.R.; Ahmed, S.M.; Abu-Rub, H. A novel three-phase to five-phase transformation using a special transformer connection. IEEE Trans. Power Deliv. 2010, 25, 1637-1644. [CrossRef]

39. Moinoddin, S.; Iqbal, A.; Abu-Rub, H.; Khan, M.R.; Ahmed, S.M. Three-Phase to Seven-Phase Power Converting Transformer; IEEE: Piscataway, NJ, USA, 2012; Volume 27, pp. 757-766.

40. Sadiki, L.; ElHani, S.; Ouachtouk, I.; Guedira, S. Optimized Feed of Six Phase Induction Machine Using Special Transformers. In Proceedings of the 2020 International Conference on Electrical and Information Technologies, Rabat-Salé, Morocco, 4-7 March 2020; pp. 2020-2022.

41. Abdelwanis, M.I.; Sehiemy, R.A.; Hamida, M.A. Hybrid optimization algorithm for parameter estimation of poly-phase induction motors with experimental verification. Energy AI 2021, 5, 1-15. [CrossRef]

42. Barrero, F.; Duran, M.J. Recent advances in the design, modeling, and control of multiphase machines-Part I. IEEE Trans. Ind. Electron. 2016, 63, 449-458. [CrossRef]

43. Duran, M.J.; Barrero, F. Recent advances in the design, modeling, and control of multiphase machines-Part II. IEEE Trans. Ind. Electron. 2016, 63, 459-468. [CrossRef]

44. Renukadevi, G.; Rajambal, K. Modeling and analysis of multi-phase inverter fed induction motor drive with different phase numbers. WSEAS Trans. Syst. Control 2013, 8, 73-80.

45. Heidari, H.; Rassõlkin, A.; Holakooie, M.H.; Vaimann, T.; Kallaste, A.; Belahcen, A.; Lukichev, D.V. A parallel estimation system of stator resistance and rotor speed for active disturbance rejection control of six-phase induction motor. Energies 2020, $13,1121$. [CrossRef]

46. Shata, A.M.; Abdel-khalik, A.S.; Member, S.; Hamdy, R.A.; Member, S.; Mostafa, M.Z. Improved Mathematical Modeling of Six Phase Induction Machines Based on Fractional Calculus. IEEE Access 2021, 9, 53146-53155. [CrossRef] 
47. Boldea, I.; Moldovan, A.; Tutelea, L. Scalar V/f and I-f control of AC motor drives: An overview. In Proceedings of the Joint International Conference-ACEMP 2015: Aegean Conference on Electrical Machines and Power Electronics, OPTIM 2015: Optimization of Electrical and Electronic Equipment and ELECTROMOTION 2015: International Symposium on Advanced Electromechanical Moti, Side, Turkey, 2-4 September 2015; pp. 8-17.

48. Munoz-Garcia, A.; Lipo, T.A.; Novotny, D.W. A New Induction Motor V/f Control Method Capable of High-Performance Regulation at Low Speeds. IEEE Trans. Ind. Appl. 1998, 34, 813-819. [CrossRef]

49. Shah, D.; Nandi, S. Analytical approach to design of slip-controller for constant Volts/Hz scheme induction motor drive using motor name-plate details. In Proceedings of the Canadian Conference on Electrical and Computer Engineering, Vancouver, BC, Canada, 5-8 May 2007; pp. 393-396. 